\title{
O DIREITO AO ESQUECIMENTO NA ESFERA INTERNACIONAL: ESTUDO COMPARATIVO DE SISTEMAS PARA CONCRETIZAÇÃO GARANTISTA NO BRASIL
}

\author{
Gabriela de Vasconcelos Sousa ${ }^{1}$ \\ Sérgio Henriques Zandona Freitas ${ }^{2}$
}

\section{RESUMO:}

A partir do método científico hipotético-dedutivo e do referencial teórico estabelecido no julgamento do Tema 786, em que o Supremo Tribunal Federal decidiu acerca da (in)existência do direito ao esquecimento no Brasil, a presente pesquisa visa analisar o problema considerando entendimento adotado sobre o assunto no cenário mundial.

Palavras-chave: Direito ao Esquecimento; Direito Comparado; Privacidade; Sociedade Digital; Memória Coletiva

\section{THE RIGHT TO BE ALONE IN THE INTERNATIONAL SPHERE: COMPARATIVE STUDY OF SYSTEMS FOR GUARANTEE IMPLEMENTATION IN BRAZIL}

\begin{abstract}
:
Based on the hypothetical-deductive scientific method and the theoretical framework established in the judgment of Theme 786, in which the Supreme Court ruled on the (in)existence of the right to be forgotten in Brazil, this research aims to analyze the problem considering understanding adopted on the subject on the world stage.
\end{abstract}

Keywords: Right to be forgotten; Comparative Law; Privacy; Digital Society; Collective Memory

\section{INTRODUÇÃO}

Um dos grandes dilemas do século XXI, conhecido também como a era da difusão da informação propagada principalmente por meio digital é a preservação da intimidade dos cidadãos em todo o mundo. Qualquer tipo de informação é veiculada pela mídia e

\footnotetext{
${ }^{1}$ Graduada em Direito e Mestranda pela Universidade FUMEC. Advogada atuante em Belo Horizonte. E-mail: gabrielavsousa@ hotmail.com.*

${ }^{2}$ Coordenador do Programa de Pós-Graduação Stricto Sensu em Direito (PPGD) da Universidade FUMEC. PósDoutor em Direito pelo Programa de Pós-Graduação Stricto Sensu em Direito (PPGD) da Universidade do Vale do Rio dos Sinos - UNISINOS (São Leopoldo/RS). Pós-Doutor em Democracia e Direitos Humanos pela Faculdade de Direito da Universidade de Coimbra (Portugal). Doutor, Mestre e Especialista em Direito pela Pontifícia Universidade Católica de Minas Gerais (PUC MINAS). Professor da Faculdade de Ciências Humanas, Sociais e da Saúde (FCH) da Universidade FUMEC, aonde é docente permanente da Graduação, Especialização e do Programa de Pós-Graduação. E-mail: sergiohzf@ fumec.br. *
} 
principalmente pelos smartphones a todo instante, sendo que não importa se esses fatos são ounão verdadeiros para muitos daqueles que compartilham as notícias.

O problema da presente pesquisa, considerando essa difusão instantânea de informação, se dá quando os fatos divulgados fazem parte do passado de um indivíduo, que tenta a todo custo esquecer um erro ou um trauma eventualmente vivenciado para assim, prosseguir com a sua vida.

Certamente, existem acontecimentos que podem ser utilizados contra a imagem de uma pessoa de forma pejorativa, podendo acarretar consequências graves para aquele que deseja ser esquecido, mesmo que anos tenham se passado anos após uma tragédia vivenciada ou erro praticado que maculou sua imagem.

Nesse sentido, no presente trabalho científico, o direito de ser esquecido é observado como um problema e fator mundial, sendo que em muitos países já existem leis ou posicionamentos jurisprudenciais a favor da aplicação do instituto, diferente do que ocorre no Brasil.

Recentemente, o Supremo Tribunal Federal julgou o tema de repercussão geral 786, em que se discutia a aplicabilidade do direito ao esquecimento, demandado pela família de AídaCuri, jovem brutalmente assassinada no Rio de Janeiro em 1958. Em 2004, o programa "LinhaDireta", transmitido pela Rede Globo de televisão realizou a reconstituição dos fatos ocorridos, ou seja, quase cinquenta anos após a tragédia, o que gerou incômodo na família da jovem, queentendeu pela judicialização da questão.

No entendimento da Suprema Corte do Brasil restou decidido que o direito ao esquecimento não seria compatível com a Constituição de 1988, além de que não existe nenhuma lei brasileira acerca da temática, mas que, no entanto, casos de eventuais excessos ou abusos no exercício da liberdade de expressão e informação devem ser analisados por si pelos tribunais brasileiros, entendimento que dá abertura para interpretações e consequentemente insegurança jurídica.

Assim, a partir do método científico hipotético-dedutivo e do referencial teórico estabelecido no julgamento do tema de repercussão geral 786, da Suprema Corte do Brasil, estapesquisa visa realizar uma análise da problemática do esquecimento no aspecto global.

O presente trabalho foi dividido em cinco capítulos, sendo introdução, três tópicos de desenvolvimento e a conclusão, podendo destacar: o direito ao esquecimento no Brasil, por meio da análise a partir da vedação das penas perpétuas no país e do entendimento 
jurisprudencial; entendimento do Supremo Tribunal Federal no julgamento do tema 786 caso Aída Curi; o caso da chacina da Candelária e entendimento do Superior Tribunal de Justiça - Recurso Especial n ${ }^{\circ}$ 1.334.097 - RJ; a relação entre os precedentes judiciais acerca do direito ao esquecimento no Brasil e o dispositivo da Constituição de 1988 que veda penas perpétuas; o entendimento do Tribunal de Justiça da União Europeia sobre o direito ao esquecimento; o caso Google Spain s.l inc; o impacto do julgamento do Tribunal de Justiça Europeu no cenário internacional; o direito ao esquecimento nos países do mundo; com destaque para américa latina: o direito ao esquecimento no Chile a partir do julgamento do rol: $\mathrm{n}^{\mathrm{o}}$ 22.243/2015; as origens do esquecimento: análise do precedente da Alemanha; o direito de ser "deixado em paz": Estados Unidos da América; e o não reconhecimento do esquecimento na Áustria.

Para a realização da pesquisa foram analisados artigos científicos acerca do assunto, legislação brasileira e estrangeira e também o entendimento jurisprudencial de alguns países do mundo. A importância da pesquisa se dá a partir do momento que se compreende a lógica da aplicação do direito de ser esquecido em outros países e o estudo comparado desse regramento com o cenário que ocorre no Brasil.

\section{O DIREITO AO ESQUECIMENTO NO BRASIL: UMA ANÁLISE A PARTIR DA VEDAÇÃO DAS PENAS PERPÉTUAS NO PAÍS E DO ENTENDIMENTO JURISPRUDENCIAL}

O primeiro capítulo do presente artigo científico visa analisar o direito de ser esquecido no Brasil, também conhecido mundialmente como "right to be alone", ou seja, direito de ser deixado em paz. Além disso, aborda sobre a vedação de penas perpétuas no nosso país e a necessidade da ressocialização de quem infringe alguma regra do ordenamento jurídico pátrio. Além disso, estuda dois precedentes judiciais no Brasil, principalmente o recente entendimento adotado pelo Supremo Tribunal Federal ao decidir sobre a temática.

\subsection{ENTENDIMENTO DO SUPREMO TRIBUNAL FEDERAL NO JULGAMENTO}




\section{DO TEMA 786 - CASO AÍDA CURI}

Em primeiro lugar, o direito ao esquecimento no Brasil se tornou uma pauta notoriamente importante a partir da ação de reparação civil ajuizada pela família de Aída Jacob Curi, assassinada e arremessada de um prédio situado em Copacabana, no Rio de Janeiro em 14 de julho de 1958. A tragédia retomou o centro das atenções no ano de 2004, após os fatos terem sido reconstituídos no programa "Linha Direta", televisionado pela Rede Globo.

A família da vítima Aída Curi buscou em juízo uma reparação civil em face da emissora, sustentando que a reconstituição do evento após o decurso de grande lapso temporalsomente ensejou a abertura de feridas passadas. $\mathrm{O}$ recurso extraordinário no caso de Aída, cerne e marco teórico do presente estudo, foi interposto contra o acórdão proferido pela $15^{\text {a }}$ Câmara Cível do Tribunal de Justiça do Estado do Rio de Janeiro, in verbis:

EMENTA: INDENIZATÓRIA. PROGRAMA 'LINHA DIRETA JUSTIÇA'. AUSÊNCIA DE DANO. Ação indenizatória objetivando a compensação pecuniária e a reparação material em razão do uso, não autorizado, da imagem da falecida irmã dos Autores, em programa denominado 'Linha Direta Justiça'. 1- Preliminar - o juiz não está obrigado a apreciar todas as questões desejadas pelas partes, se por uma delas, mais abrangente e adotada, as demais ficam prejudicadas. 2- A Constituição Federal garante a livre expressão da atividade de comunicação, independente de censura ou licença, franqueando a obrigação de indenizar apenas quando o uso da imagem ou informações é utilizada paradenegrir ou atingir a honra da pessoa retratada, ou ainda, quando essa imagem/nome for utilizada para fins comerciais. Os fatos expostos no programa eram do conhecimento público e, no passado, foram amplamente divulgados pela imprensa. A matéria foi, é discutida e noticiada ao longo dos últimos cinquenta anos, inclusive, nos meios acadêmicos. A Ré cumpriu comsua função social de informar, alertar e abrir o debate sobre o controvertido caso. Os meios de comunicação também tem este dever, que se sobrepõe ao interesse individual de alguns, que querem e desejam esquecer o passado. $O$ esquecimento não é o caminho salvador para tudo. Muitas vezes é necessário reviver o passado para que as novas gerações fiquem alertadas e repensem alguns procedimentos de conduta do presente. Também ninguém nega que aRé seja uma pessoa jurídica cujo fim é o lucro. Ela precisa sobreviver porque gera riquezas, produz empregos e tudo mais que é 
notório no mundo capitalista. O que se pergunta é se o uso do nome, da imagem da falecida, ou a reprodução midiática dos acontecimentos, trouxe um aumento do seu lucroe isto me parece que não houve, ou se houve, não há dados nos autos. Recursodesprovido, por maioria, nos termos do voto do Desembargador Relator (TJ-RJ Apelação Cível $\mathrm{n}^{\mathrm{o}}$ 0123305-77.2004.8.19.0001, Relator: Des. Ricardo rodrigues Cardozo, Décima Quinta Câmara Cível, Data de Publicação: Diário da Justiça, 17 de agosto de 2010) (RIO DE JANEIRO, 2010).

Na esteira do entendimento do Relator do caso, Desembargador Ricardo Rodrigues Cardozo: "O esquecimento não é o caminho salvador para tudo. Muitas vezes é necessário reviver o passado para que as novas gerações fiquem alertadas e repensem alguns procedimentos de conduta do presente" (RIO DE JANEIRO, 2010).

Apesar do caso ter sido julgado improcedente pelo Tribunal de Justiça do Rio de Janeiro, no ano anterior ao julgamento, o Superior Tribunal de Justiça editou a Súmula 403, definindo que: "Independe de prova do prejuízo a indenização pela publicação não autorizada de imagem de pessoa com fins econômicos ou comerciais" (BRASIL, 2010).

Frisa-se que o Superior Tribunal de Justiça também negou provimento ao recurso especial interposto no caso, oportunidade em que compreendeu que a Súmula supracitada não seria aplicável ao tema em questão.

Por sua vez, em 11 de fevereiro de 2021, o Supremo Tribunal Federal reconheceu a repercussão geral do assunto, sendo que a tese aprovada ao decidir o Tema 786 foi a seguinte:

É incompatível com a Constituição a ideia de um direito ao esquecimento, assim entendido como um poder de obstar, em razão da passagem do tempo, a divulgação de fatos ou dados verídicos e licitamente obtidos e publicados em meios de comunicação social analógicos ou digitais. Eventuais excessos ou abusos no exercício da liberdade de expressão e de informação devem seranalisados caso a caso, a partir dos parâmetros constitucionais, especialmente os relativos à proteção da honra, da imagem, da privacidade e da personalidade em geral, e as expressas e específicas previsões legais nos âmbitos penal e cível (BRASIL, 2021).

A Suprema Corte entendeu que não existe o direito ao esquecimento no Brasil em razão da divulgação de fatos pretéritos em instrumentos midiáticos. No entanto, deixou em aberto um precedente para a solução de eventuais abusos no exercício da liberdade de 
expressãoe informação a serem analisados caso a caso pelo Poder Judiciário.

Sendo assim, o que se pode verificar a partir da tese firmada é que a questão não foi efetivamente decidida pela Suprema Corte Brasileira, pois não se fixou um critério objetivo para avaliar o que caracterizaria ou não um abuso no uso da liberdade de informar no país.

\subsection{CASO DA CHACINA DA CANDELÁRIA E ENTENDIMENTO DO SUPERIOR TRIBUNAL DE JUSTIÇA -RECURSO ESPECIAL N 1.334.097 - RJ}

Lado outro, existe na jurisprudência brasileira um caso em que o direito ao esquecimento foi conferido pelo Superior Tribunal de Justiça em ação judicial também pleiteada em face da Rede Globo, mesmo que alguns anos antes do posicionamento do Supremo Tribunal Federal.

Em junho de 2006 o programa televisivo "Linha Direta" apresentou a reconstituição dos fatos conhecidos como a "Chacina da Candelária", ocorrida em 1993, também na cidade do Rio de Janeiro, oportunidade em que oito pessoas foram assassinadas. Um dos investigados pela prática do crime, absolvido pela justiça, foi procurado pela rede televisiva para conceder uma entrevista ao programa, sendo que mesmo após a sua recusa o seu nome foi apontado comoum dos envolvidos no ato pelo programa transmitido em rede nacional.

O autor da ação, Jurandir Gomes de França, alegou que a exposição da sua imagem foi ilícita e lhe causou severo abalo moral, ocasião em que a Rede Globo foi condenada a pagar pelos danos causados.

\subsection{A RELAÇÃO ENTRE OS PRECEDENTES JUDICIAIS ACERCA DO DIREITO AO ESQUECIMENTO NO BRASIL E O DISPOSITIVO DA CONSTITUIÇÃO DE 1988 QUE VEDA PENAS PERPÉTUAS}

No Brasil, o que podemos perceber a partir da análise jurisprudencial pátria, é que o julgamento acerca do direito ao esquecimento pelo Supremo Tribunal Federal, com a 
ressalva de que eventuais abusos praticados pelos veículos de informação deverão ser analisados caso acaso, é que a insegurança jurídica poderá vigorar no país a partir de então.

A Constituição de 1988, além de assegurar como um dos fundamentos da República a dignidade da pessoa humana, estabelece em seu artigo $5^{\circ}$ que:

Todos são iguais perante a lei, sem distinção de qualquer natureza, garantindo-se aos brasileiros e aos estrangeiros residentes no País a inviolabilidade do direito à vida, à liberdade, à igualdade, à segurança e à propriedade [...]

XLVII - não haverá penas: [...]

b) de caráter perpétuo. (BRASIL, 1988).

Ao realizar uma analogia entre a vedação as penas de caráter perpétuo no Brasil e o não reconhecimento do direito ao esquecimento pela Suprema Corte do país, confrontados coma dignidade da pessoa humana, nos encontramos em meio a uma situação problemática, visto que em muitas situações, em que indivíduos são encarceradas pelo cometimento de algum delito acabam sendo punidos eternamente pela própria sociedade, mesmo após o cumprimento da suapena.

Até mesmo indivíduos absolvidos pela justiça continuam sendo rememorados pela sociedade a partir do momento em que alguma tragédia ocorrida, em que este foi apontado porum suposto envolvimento é relembrada, como ocorreu no caso da Chacina da Candelária.

Em tese, a proteção da dignidade da pessoa humana, assegurada pela Constituição de 1988, deveria garantir o tratamento dos cidadãos como sujeitos de valor superior a tudo aquilo que foi criado pelas mãos da própria humanidade, como é o caso da imprensa e do mercado de capitais.

Nesse sentido, o filósofo Immanuel Kant apresentou a seguinte abordagem:

Agora eu afirmo: o homem - e, de uma maneira geral, todo o ser racional - existe como fim em si mesmo, e não apenas como meio para o uso arbitrário desta ou daquela vontade. Em todas as suas ações, pelo contrário, tanto nas direcionadas a ele mesmo como nas que o são a outros seres racionais, deve ser ele sempre considerado simultaneamente como fim. Todos os objetos das inclinações têm um valor apenas condicional, pois se não existissem as inclinações e as necessidades que nelas se fundamentam seria sem valor o seu objeto. As próprias inclinações, porém, como fontes das necessidades, tão longe estão de possuir um valor absoluto que as torne desejáveis em si mesmas que, muito pelo contrário, melhor deve ser o desejo universal de todos os seres racionais em libertar-se totalmente delas. 
Portanto, o valor de todos os objetos que possamos adquirir pelas nossas ações é sempre condicional. Os seres, cuja existência não assenta em nossa vontade, mas na natureza, têm, contudo, se são seres irracionais, um valor meramente relativo, como meios, e por isso denominam-se coisas, ao passo que os seres racionais denominam-se pessoas, porque a sua natureza os distingue já como fins em si mesmos, ou seja, como algo que não pode ser empregado como simples meio e que, portanto, nessa medida, limita todo o arbítrio (e é um objeto de respeito). (KANT, 2009, p. 35).

Tratar sobre um possível direito ao esquecimento nos leva a uma reflexão sobre o próprio perdão, sendo que a partir do momento em que ele não é exercitado pela sociedade como um todo, inclusive pelo Poder Judiciário, uma série de direitos fundamentais são violados, inclusive aquele que veda as penas perpétuas no Brasil.

Completando a abordagem sobre a temática, Pablo Dominguez Martinez configura o direito ao esquecimento como um direito fundamental, em que a memória de um individuo é fator inviolável por terceiros de forma desmedida. Nesse sentido:

O direito ao esquecimento é um direito fundamental que seu titular tem de se resguardar daquilo que não deseja rememorar. Trata-se do direito de não ter sua memória pessoal revirada a todo instante, por força da vontade de terceiros. Como tal, configura-se como um direito essencial ao livre desenvolvimento da personalidade humana. (MARTINEZ, 2014, p. 41).

Conclui-se, considerando o cenário brasileiro, que a questão do esquecimento caminha a passos lentos, o que não diminui a importância do seu exercício e aplicação, até mesmo para assegurar que um indivíduo não seja eternamente punido por determinado fato ocorrido ao longo de sua vida, efetivando os direitos constitucionais da dignidade do homem e da vedaçãodas penas perpétuas.

\section{O ENTENDIMENTO DO TRIBUNAL DE JUSTIÇA DA UNIÃO EUROPEIA SOBREO DIREITO AO ESQUECIMENTO}

No segundo capítulo da presente pesquisa, passando para a análise do direito ao esquecimento enquanto fenômeno mundial, realiza-se um estudo do caso emblemático 
acerca da questão, que foi julgado pela Suprema Corte da Europa, órgão internacional.

\subsection{CASO GOOGLE SPAIN S.L INC}

No ano de 2010, Mario Costeja González, nacional da Espanha, ajuizou uma ação de reparação de danos contra as empresas Google Spain e Google Inc. na Agência Espanhola de Proteção de Dados, conhecida como AEDP, sustentando que ao realizar uma busca pelo seu nome na plataforma Google surgiam dois links que indicavam páginas do jornal europeu "La Vanguardia”, ambas do ano de 1988 que indicavam dívidas previdenciárias do Autor.

$\mathrm{Na}$ tentativa de proteger os seus dados, o autor da ação solicitou que o site retirasse ourealizasse a alteração das páginas, além de requerer que a Google removesse ou ocultasse as informações relativas à sua pessoa nos resultados de busca.

O pleito do cidadão foi negado em relação ao jornal "La Vanguardia", tendo em vistaque as informações relacionadas as dívidas do autor foram publicadas de forma legal. No entanto, o pedido foi julgado procedente em relação à Google Spain e Google Inc., para que ambas tomassem as atitudes necessárias para retirar os dados pessoais do autor da rede de busca.

Inconformadas, as empresas apresentaram recurso para a Audiência Nacional (National High Court), sendo que o processo foi suspenso e encaminhado para julgamento perante o Tribunal de Justiça da União Europeia.

O entendimento do Tribunal de Justiça da União Europeia ao julgar o caso em 2014 levou em conta o disposto nos artigos $7^{\circ}$ e $8^{\circ}$ da Carta dos Direitos Fundamentais da União Europeia, que, ambos traduzidos para a língua portuguesa prescrevem que:

Art. $7^{\circ}$ Respeito pela vida privada e familiar

Todas as pessoas têm direito ao respeito pela sua vida privada e familiar, peloseu domicílio e pelas suas comunicações.

Art. $8^{\circ}$ Proteção de dados pessoais

1. Todas as pessoas têm direito à proteção dos dados de caráter pessoal que lhes digam respeito.

2. Esses dados devem ser objeto de um tratamento leal, para fins específicos e com o consentimento da pessoa interessada ou com outro fundamento legítimo previsto por lei. Todas as pessoas têm o direito de aceder aos dados coligidos que lhes digam respeito e de 
obter a respectiva retificação.

3. O cumprimento destas regras fica sujeito a fiscalização por parte de umaautoridade independente. (UNIÃO EUROPEIA, 2000).

A partir dos dispositivos legais supramencionados restou fixado o entendimento de que o operador de busca é o responsável pelo tratamento dos dados pessoais presentes em seus mecanismos, sendo que, mesmo que os dados tenham sido publicados por terceiros de forma lícita, com o transcurso temporal as informações se tornariam desnecessárias e inadequadas para aquele que foi exposto e também para a sociedade.

Sendo assim, o entendimento consolidado foi que os direitos fundamentais à privacidade e proteção de dados pessoais seriam violados a partir do momento em que um cidadão tenha negado o pedido de remoção de links de pesquisa envolvendo o seu nome. A partir disso, o direito ao esquecimento foi reconhecido por essa Corte Suprema.

\subsection{IMPACTO DO JULGAMENTO DO TRIBUNAL DE JUSTIÇA EUROPEU NO CENÁRIO INTERNACIONAL}

O Tribunal de Justiça da União Europeia exerceu grande impacto no âmbito internacional ao julgar o caso Google Spain e Google Inc., tendo em vista que forçou os demais países a refletirem acerca da pertinência das informações pessoais dos indivíduos que se encontrem disponíveis na rede pública de informações ou que sejam publicadas fora de um contexto temporal.

Sobre o julgado na Europa Bruno de Lima Acioli e Marcos Augusto de Albuquerque Ehrhardt Júnior ainda realizaram em sua pesquisa acadêmica as seguintes considerações:

[...] com a mudança de paradigma do puro controle espacial do direito de serdeixado em paz, que lidava somente com a presença ou ausência de consentimento da pessoa em partilhar determinada informação, para a sua complementação pelas hipóteses de controle contextual e temporal, os processadores de dados precisam se adequar para, também, observar o contexto e o propósito do recolhimento e processamento de uma informação.Da mesma forma, legisladores e juízes, também, devem se adequar a esse novo paradigma [...]. (ACIOLI; EHRHART, 2017). 
Em que pese o entendimento consolidado no continente europeu, a questão do esquecimento ainda não alcança o panorama ideal ao redor do mundo. No entanto, por se tratar um órgão internacional, o julgado abriu as portas para uma mudança de paradigma sobre a proteção de dados na internet, porque considerou que estamos vivenciando a era da rápida propagação de informação, que nem sempre podem ser consideradas pertinentes a partir docontexto em que foram difundidas.

\section{O DIREITO AO ESQUECIMENTO NOS PAÍSES DO MUNDO}

Por fim, o último capítulo da pesquisa aborda como o direito ao esquecimento foi tratado em diversos países do mundo, sendo que, na América Latina, já existe precedente em favor da existência deste direito.

\subsection{AMÉRICA LATINA: O DIREITO AO ESQUECIMENTO NO CHILE A PARTIR DO JULGAMENTO DO ROL: N²2.243/2015}

Em janeiro de 2016, a Suprema Corte do Chile se mostrou favor da existência do direito ao esquecimento no julgamento do Rol no 22.243-2015. Um cidadão chileno postulou a remoção de um link nos locais de busca da internet de uma notícia veiculada que publicou um fato delituoso cometido por ele anos atrás.

Após dez anos do cumprimento da sua pena, o homem entendeu que aquela informação possuía impactos negativos para a sua ressocialização, além de macular a imagem da sua família. A Suprema Corte decidiu pela existência do direito ao esquecimento, eis que jánão existia mais interesse público na manutenção da página, além da antiguidade da notícia.

A partir de critérios de ponderação entre direitos fundamentais, restou decidido que aquilo ali divulgado violava o direito à honra e à privacidade do homem, bem como de sua família. Sobre o assunto, Pierina Andrea Aimone Cabrera afirma que:

No Chile o direito ao esquecimento foi desenvolvido pela primeira vez no direito penal. Em caso de conflito entre o direito ao 
esquecimento do passado judicial (à supressão da informação sobre antecedentes penais e condenaçõespassadas) e o direito à informação (acesso a essa informação). O fator tempoé usado como um critério decisivo: se a informação considera-se de interesse jornalístico (pela atualidade de sua ocorrência), o direito à informação prevalece; senão o direito ao esquecimento prevalece sobre o direito à informação (ainda é possível ver a sentença, mas não se tem o nome dos implicados). (CABRERA, 2016).

Em razão da proximidade geográfica e aproximação governamental o caso ocorrido no Chile pode servir como estímulo na busca de maneiras de ressocialização e inclusão de pessoas que já foram encarceradas, se tratando de um verdadeiro exemplo para toda a AméricaLatina.

\subsection{AS ORIGENS DO ESQUECIMENTO: ANÁLISE DO PRECEDENTE DA ALEMANHA}

No ano de 1969 ocorreu o assassinato de quatro soldados no momento em que dormiam, sendo que os criminosos foram processados e condenados à pena de prisão perpétua.

Anos depois do ocorrido, uma rede televisa alemã produziu uma reportagem a respeito da ocorrência, mencionando até os nomes dos autores daquela prática delituosa (COLNAGO; AMARAL, 2018).

Por entender que os seus direitos fundamentais foram violados, um dos condenados entendeu por judicializar a questão para impedir que a veiculação da reportagem. Em primeira instância os pedidos foram julgados improcedentes, sendo que após a interposição de recursos, a situação partiu para a análise do Tribunal Constitucional Alemão.

O recurso do homem foi provido pela Suprema Corte, partindo da premissa da importância da ressocialização dos autores do crime, que a partir da ponderação e do sopesamento entre direitos, se demonstrava mais relevante do que o direito à informação no caso concreto, fato que abriu precedente para o reconhecimento da tese do direito ao esquecimento.

Sendo assim, na Alemanha foi reconhecido o direito ao esquecimento. 


\subsection{O DIREITO DE SER “DEIXADO EM PAZ”: ESTADOS UNIDOS DA AMÉRICA}

Nos Estados Unidos da América, o direito ao esquecimento ganhou notoriedade pela conceituação "the right to be alone", expressão que ao ser traduzida para a língua portuguesa significa o "direito de ser deixado em paz".

Esse conceito demonstra, da mesma forma que no Brasil ao ser mencionado, a busca pelo direito ao esquecimento, que tem como objetivo principal "deixar o indivíduo em paz”, ou seja, não insistir em erros cometidos no passado, erros pelos quais o agente que praticou se arrepende.

Ao partir para a pesquisa sobre o direito ao esquecimento nos Estados Unidos, Daniel Blume Pereira de Almeida afirma que "nos Estados Unidos, o direito à publicação do registro criminal encontra-se protegido pela First Amendment da Constituição Americana. Então podemos dizer: o que foi feito e o que foi dito foi dito, ninguém pode apagar." (ALMEIDA, 2007, p. 12). Sendo assim, em regra, ao se tratar de matéria criminal, nos Estados Unidos prevalece odireito de informação.

No entanto, existe um precedente importante acerca da temática no país, caso Melvin vs Reid, julgado pelo Tribunal de Apelação da Califórnia em 1931. Trata-se de demanda em que Gabrielle Darley abandonou a prostituição e foi inocentada do cometimento de umhomicídio ocorrido em 1918. Em 1925, foi produzido um filme baseado na história de Gabrielle. O filme "Red Kimono", dirigido por Doroty Reid, transmitia com precisão de detalhes a trajetória de Gabrielle, sendo que seu marido Melvin buscou judicialmente a reparação dos danos causados pela produção artística (PEREIRA FILHO, 2019).

O Tribunal da Califórnia acatou os pedidos de Melvin, sob a argumentação de que os fatos vividos por Gabrielle não poderiam prejudicar a sua reputação ou violar os seus direitos à personalidade.

\subsection{O NÃO RECONHECIMENTO DO ESQUECIMENTO NA ÁUSTRIA}

$\mathrm{Na}$ realização da presente pesquisa acadêmica, demonstrou-se também impressionante o precedente austríaco. 
Em 2012, a Suprema Corte da Áustria decidiu que seria constitucional uma norma queadmitisse a manutenção de um registro acerca de um processo penal pelo lapso temporal de até 60 (sessenta anos), no julgamento G 7/12-11. Um cidadão absolvido pela suposta prática do crime de possuir material pornográfico envolvendo crianças pleiteou perante a Comissão de Proteção de Dados a exclusão das informações do processo ao qual ele respondia perante o banco de dados de uso da polícia, procuradoria e tribunais (ÁUSTRIA, 2012).

Sendo assim, a partir de uma norma que permite o registro de causas judiciais criminais específicas, o homem entrou com uma ação buscando a declaração da inconstitucionalidade da lei, sob a argumentação da violação a sua privacidade.

A decisão tomada pelo Tribunal Constitucional da Áustria foi no sentido de que que a lei é constitucional. Para o Tribunal austríaco não foram vislumbrados elementos capazes de ensejar a declaração de inconstitucionalidade da lei impugnada. Para tanto, foi exposto que o prazo de sessenta anos seria apenas um parâmetro máximo, sendo que a partir de uma análise da autoridade competente do julgamento poderia ser mais curto, observada a proporcionalidade.

\section{CONCLUSÃO}

Considerados os tópicos que foram abordados na presente pesquisa científica, conclui-se que embora o estudo do direito ao esquecimento não tenha evoluído de forma consideravelmente adequada no Brasil, que não tem nenhuma legislação específica acerca da temática, em muitos países no âmbito global a sua aplicação já foi garantida, seja pelo legisladorou pela própria jurisprudência pátria.

Relevante foi o julgamento do Tribunal de Justiça da Europa sobre a temática, que entendeu pela existência desse direito ao tratar da preservação de dados pessoais de um indivíduo, que embora tenham sido difundidos de forma verdadeira em razão de uma situação vexatória no passado, já não possuíam mais uma razão para se encontrarem presentes e serem difundidos em mecanismos de busca na internet.

Além do julgamento na Europa, é importante também o precedente chileno, país que compõe a América Latina e demonstrou a preocupação com a questão do perdão e 
ressocialização do indivíduo que comete um ano delituoso e cumpre o que é devido em relação a justiça pátria.

No cenário brasileiro, o estudo do esquecimento é extremamente relevante.

Em primeiro lugar, quando a Constituição de 1988 trata sobre os direitos e garantias fundamentais dos cidadãos, existe a vedação da prisão perpétua e da pena de morte, sendo que a última só é admitida em caso de guerra declarada. Em segundo lugar, conforme observado no presente artigo, a Lei de Execução Penal do Brasil assegura que a função da pena é a integração social do condenado, ou seja, a sua ressocialização.

Ora, considerando o cenário de preconceito e desigualdade social que vigoram no Brasil, como é possível dar efetividade a ressocialização de um indivíduo sendo que não se preocupa com a questão do esquecimento e do perdão? Será que o desenvolvimento do país fica comprometido a partir do momento em que as pessoas uma vez encarceradas pela prática de algum delito se tornam seres excluídos por toda a sociedade?

De fato, as questões acima levantadas são passíveis de inúmeras reflexões e poucas respostas considerando o cenário jurídico atual, no entanto, de extrema relevância, principalmente levando em conta que o Brasil é um dos países que mais encarcera pessoas no mundo.

A partir do momento que não se permite a ressocialização de pessoas por máculas em seu passado estar-se-á inviabilizando a chance de um possível recomeço e comprometendo o avanço do Brasil, levando indivíduos a continuarem vivendo a margem da sociedade, sujeitos a reincidirem em práticas delituosas pela ausência não só de caráter, mas também de oportunidades.

\section{REFERÊNCIAS}

ACIOLI, Bruno de Lima; EHRHARDT JÚNIOR, Marcos Augusto de Albuquerque. Uma agendapara o direito ao esquecimento no Brasil. Revista brasileira de políticas públicas, v. 7, n. 3, p. 383-410, 2017. Disponível em:

https://eventos.set.edu.br/sempesq/article/view/12750. Acesso em: 15 ago. 2021.

ÁUSTRIA. Suprema Corte da Áustria. Im namen der republik!. G 7/12- 11-29. Jun. 2012. Disponível em:

http://e.tribunalconstitucional.cl/img/Attachment/143/g7_12_speicherfrist.pdf. Acesso em: 
10 ago. 2021.

BRASIL. Boletim de Jurisprudência Internacional: Direito ao Esquecimento. Supremo Tribunal Federal. 2018. Disponível em:

http://www.stf.jus.br/arquivo/cms/jurisprudenciaInternacional/anexo/BJI5DIREITOAOES QU ECIMENTO.pdf. Acesso em: 14 ago. 2021.

BRASIL. Constituição (1988). Constituição da República Federativa do Brasil de 1988. Presidência da República. Casa Civil. Subchefia para Assuntos Jurídicos. Brasília, DF, 05 out.1988. Disponível em: http://www.planalto.gov.br/ccivil_03/leis/17210.htm. Acesso em: 10 ago. 2021.

BRASIL. Superior Tribunal de Justiça. Enunciado 531 da VI Jornada de Direito Civil. Atutela da dignidade da pessoa humana na sociedade da informação inclui o direito ao esquecimento. CJF. Enunciados, 2013. Disponível em:

https://www.cjf.jus.br/enunciados/enunciado/142. Acesso em: 10 ago. 2021.

BRASIL. Superior Tribunal de Justiça. Recurso Especial 1334097/RJ, $4^{\text {a }}$ Turma, Relator Ministro Luis Felipe Salomão. Diário de Justiça Eletrônico, 10 de setembro de 2013. Disponível em: https://www.stj.jus.br/sites/portalp/Inicio. Acesso em: 12 ago. 2021.

BRASIL. Supremo Tribunal Federal. Recurso Extraordinário 1.010.606/RJ.

Recorrentes Nelson curi e outro(a/s) Recorrida: Globo comunicacao e participacoes s/a. Disponível em: http://portal.stf.jus.br/processos/detalhe.asp?incidente=5091603. Acesso em: 11 ago. 2021.

CABRERA, Pierina Andrea Aimone. Direito ao esquecimento na internet: Uma comparaçãoentre as legislações do Brasil e Chile. Disponível em:

http://www.stf.jus.br/repositorio/cms/portalStfInternacional/portalStfCooperacao_pt_br/an exo/Trabalhocorrigido100.pdf. Acesso em: 16 ago. 2021.

COLNAGO, Amanda Soares; AMARAL, Sérgio Tibiriçá. Direito ao esquecimento: evolução histórica e direito comparado. ETIC-Encontro de iniciação científica-ISSN 21-76-8498, v. 14, n. 14, 2018. Disponível em:

http://intertemas.toledoprudente.edu.br/index.php/ETIC/article/view/7302. Acesso em: 15 ago.2021.

COLUMBIA UNIVERSITY. Base de Jurisprudência da Columbia University (Global Freedomof Expression). Disponível

em:

https://globalfreedomofexpression.columbia.edu/cases/hashavim-h-p-s-business-data-vdirectorate- courts/. Acesso em: 15 ago. 2021.

EUROPEIA, União. Carta dos direitos fundamentais da União Europeia. Direito e Democracia, p. 457, 2007. Disponível em: https://www.researchgate.net/profile/BetaniaAlfonsin/publication/43236353_O_Estatuto_da_cidade_e_a_construcao_de_cidades_sustent a veis_justas_e_democraticas/links/5554aff108ae980ca60acf15/O-Estatuto-da-cidade-e-aconstrucao-de-cidades-sustentaveis-justas-e-democraticas.pdf\#page $=205$. Acesso em: 15 ago.2021. 
KANT, Immanuel. Fundamentação da Metafísica dos Costumes. Tradução: Guido Antônio deAlmeida. São Paulo: Discurso Editorial - Barcarolla, 2009.

MARTINEZ, Pablo Dominguez. Direito ao esquecimento. A proteção da memória individualna sociedade da informação. Rio de Janeiro: Lumem Juris, 2014.

PEREIRA FILHO, José Arthur de Carvalho. Do direito ao esquecimento. Revista Amagis Jurídica, v. 2, n. 15, p. 25-58, 2019. Disponível em: https://revista.amagis.com.br/index.php/amagis-juridica/article/view/43. Acesso em: 17 ago. 2021.

RIO DE JANEIRO. Tribunal de Justiça do Estado do Rio de Janeiro. Apelação Cível no 0123305-77.2004.8.19.0001. Relator: Des. Ricardo Rodrigues Cardozo. Décima Quinta Câmara Cível. Data de Publicação: Diário da Justiça, 17 de agosto de 2010. 